\title{
Soft Is Better: Determinants of Preferences for Non-Motorized Forms of Transportation in Urban Tourism Destinations
}

\author{
Yahua Bi ${ }^{1}\left[\right.$ and João Romão ${ }^{2, *(1)}$ \\ 1 Department of Tourism and Convention, Pusan National University, Busan 46241, Korea; \\ yahuabi@pusan.ac.kr \\ 2 Department of International Tourism Business, Yasuda Women's University, Hiroshima 731-0153, Japan \\ * Correspondence: romao-j@yasuda-u.ac.jp
}

check for updates

Citation: Bi, Y.; Romão, J. Soft Is Better: Determinants of Preferences for Non-Motorized Forms of Transportation in Urban Tourism Destinations. Sustainability 2021, 13 11944. https://doi.org/10.3390/ su132111944

Academic Editor: Wann-Ming Wey

Received: 14 September 2021

Accepted: 24 October 2021

Published: 28 October 2021

Publisher's Note: MDPI stays neutral with regard to jurisdictional claims in published maps and institutional affiliations.

Copyright: (c) 2021 by the authors. Licensee MDPI, Basel, Switzerland. This article is an open access article distributed under the terms and conditions of the Creative Commons Attribution (CC BY) license (https:/ / creativecommons.org/licenses/by/ $4.0 /)$.

\begin{abstract}
Non-motorized forms of transportation are increasingly perceived as an option that can contribute to reducing the ecological impact of the transportation of tourists while offering satisfactory opportunities to appreciate the urban environment. Walking, bicycles, and other forms of nonmotorized transport are increasingly used in urban contexts, both by residents and tourists. By looking into the characteristics and trip motivations of international tourists visiting the city of Barcelona, our analysis identifies the groups of tourists more oriented to these soft forms of mobility and also takes into consideration how they obtained previous information about the destination. Based on an extensive survey conducted in the city, the results of our multinomial logistic regressions reveal a slight generational divide when looking at sources of information (with retired tourists less oriented to digital tools) and a strong generational divide when observing transport choices (younger tourists more oriented to both soft or collective forms of mobility). Our results also show that tourists traveling in groups and/or with trips organized by travel companies and other organizations tend to prefer the utilization of private cars. These results can be used to promote the non-motorized mobility of tourists in other urban destinations.
\end{abstract}

Keywords: soft modes of transportation; non-motorized transports; market segmentation; trip motivation; information; urban tourism

\section{Introduction}

In spite of the recent disruptions caused by the COVID-19 pandemics, tourism activities experienced continuous and significant growth over the last decades, in particular regarding urban destinations. These new fluxes of visitors to cities and metropolitan areas imposed new challenges in terms of mobility and transportation in order to mitigate negative environmental impacts, reduce problems of traffic congestion, and ensure efficient mobility of tourists that can favor their enjoyment of local experiences without disturbing the residents' regular movements to work and leisure.

In this context, strategies of mitigation of environmental impacts of tourism appear crucial for the future of tourism. The perceptions of the consequences of human actions on the global $\mathrm{CO}_{2}$ emissions or the utilization of non-renewable resources, in particular for energy production, contribute towards amplification of the concerns with the sustainability of contemporary economic systems and, in particular, with the sustainability of tourism, an activity which clearly relies on transportation services, both when connecting the places of origin and destination of tourists, and also when tourists move within the destination they are visiting [1,2]. In fact, tourism was already responsible for $5 \%$ of the global $\mathrm{CO}_{2}$ emissions in 2005 [3], and the number of tourists increased significantly after that-even though we observed an abrupt decrease in global travels due to the COVID-19 pandemic, it seems clear that the tourism sector will recover its dynamics in a relatively short period.

The current context of recovery of tourism after a period of crisis offers an important opportunity to rethink and reorganize the mobility and forms of transportation of 
tourists. In fact, the global emissions of $\mathrm{CO}_{2}$ caused by the transport of tourists in 2016 were estimated at 1600 million, which represents $5 \%$ of the total emissions related to the consumption of energy [4]. In particular, this report estimates that transport is responsible for $75 \%$ of the total amount of emissions related to tourism activities, with the largest contributions coming from airplanes (40\%) and cars (32\%). Additionally, acknowledging that cities are currently responsible for $70 \%$ of the global greenhouse emissions [5], these results clearly show the importance of promoting the utilization of public transports in urban destinations $[6,7]$ while also reinforcing the relevance of non-motorized forms of transportation.

It is also noteworthy that the problems caused by the mobility and transportation of tourists within urban destinations are not exclusively related to $\mathrm{CO}_{2}$ emissions. In fact, other problems can also be relevant, e.g., the congestion of roads or other transport infrastructures or the pressure on local transport networks caused by the cumulative use of tourists and residents [8]. Moreover, even the satisfaction with the tourism experience can be negatively affected by transport choices and related service provision $[9,10]$. As discussed in detail in the next section, non-motorized forms of transportation can contribute to minimizing the environmental impacts of the presence of tourists in urban centers while also contributing to better enjoyment of the amenities, landscapes, and general city atmosphere. Moreover, recent strategic approaches to urban planning suggest shifting the paradigm from a vehicle-oriented perspective to a new attitude where people and walking assume a more central role [11].

Our study aims to identify different profiles of visitors regarding their utilization of non-motorized forms of transport, taking into account travel motivations and sociodemographic characteristics, along with the types of trips undertaken, following other analyses of the determinants of transport choice in tourism destinations [12-14]. Moreover, our model also includes variables related to the sources of information used by each tourist about the destination since previous information about transport systems also appears as a relevant factor influencing transport choices in tourism destinations, as observed in the systematic literature review about public transport offered by [15].

In particular, the purpose of our work is to model, analyze, and discuss the three following questions:

$\rightarrow \quad$ How demographic features of tourists and trip characteristics are related to the sources of information used before the trip;

$\rightarrow \quad$ How these demographic and trip characteristics are related to the choice of transports in the destination, with a particular focus on non-motorized transports;

$\rightarrow$ How information sources influence transport preferences at the destination.

This multinomial regression model is described and explained in detail in the third section of our work, followed by a presentation of results and a related discussion of managerial implications and options for further research. Our comprehensive and innovative analysis of the determinants of preferences for soft modes of transportation in a well-established urban tourism destination such as Barcelona is in line with the current guidelines to reduce $\mathrm{CO}_{2}$ emissions in European cities [16] and in particular with the concerns $[17,18]$ and strategies $[19,20]$ recently assumed and implemented by local authorities. However, we expect that the analysis conducted and the results obtained can be generalized to other destinations and applied to different processes of sustainable tourism planning and management in contemporary cities.

\section{Literature Review and Conceptual Framework}

Transport choices in tourism destinations are clearly linked to the time each tourist has available for the visit, which constrains the type of movement that can be done, the related duration, and, consequently, the type of transport used. Since [21] defined the concept of "time budget" (the time available for the visit to a destination), this concept has been often used when analyzing these problems. Personal motivations and their interests (or those of the travel group they integrate), along with the previous knowledge of the destination 
(which emphasizes the importance of the information collected before traveling), are also crucial elements determining transport choices, as observed by [22].

In particular, the option between private modes of transportation and public or collective transports has been the object or relatively detailed analysis over the last decade, as the concerns with environmental problems, $\mathrm{CO}_{2}$ emissions, and the consequences of overtourism for local communities in urban destinations assume greater relevance in contemporary societies. However, even in these cases, the research is relatively insufficient, mostly due to the lack of information [2]. Most of these studies seem very dependent on the local characteristics of the networks of public transports [23], although some personal characteristics of travelers [14] or trip motivations [9] are also identified as determinants of the preferences for individual or collective forms of mobility in urban destinations.

More recently, non-motorized forms of transport gained popularity in the urban context from the point of view of local residents and tourists. Apart from the contribution to reducing the impacts of transportation on $\mathrm{CO}_{2}$ emissions, these transports have lower impacts on traffic congestion and noise pollution while potentially contributing to better enjoyment of the city landscape. Additionally, designated as "soft" modes of transportation, they can include different forms of mobility, including walking, cycling, or using other non-motorized devices such as scooters or skates (eventually with different denominations but not using non-renewable forms of energy and not contributing to $\mathrm{CO}_{2}$ emissions, along with the absence of noise). With increasing applications and developments in many contemporary cities, these forms of transportation are also increasingly adopted in tourism mobility [1,24].

In this context, several recent studies developed in different parts of the world addressed the utilization of bicycles by tourists, not only as a means of transportation to the destination $[25,26]$ but also as a form of mobility inside the cities during the visits $[1,27,28]$. Although these studies adopt different methodologies for the analysis, all of them have in common the fact that they are focused on the study of the characteristics of transport networks or urban design rather than the characteristics of the tourists preferring this type of mobility, which is the purpose of our work.

Another emerging body of literature in tourism relates to the preference of tourists for walking when visiting an urban destination. As observed by [29] in their editorial introduction for a special issue on this topic, walking is a very common practice for tourists but an almost "invisible" issue in terms of research. This special issue would include several relevant contributions, generally focused on the characteristics of local infrastructures and urban design, as it was observed for the case of utilization of bicycles [30-32]. In the same vein, other recent studies addressed similar aspects of the design or policies for cities as determinants of the preference of tourists for the utilization of bicycles [33], including different types of attempts to measure the "walkability" of cities, mostly using the "walk score index" $[29,34,35]$.

Our study adopts a different perspective to the determinants of the preferences of tourists for soft (or non-motorized) forms of transport in urban tourism destinations by taking into consideration the individual socio-demographic characteristics of tourists and the type of trip undertaken rather than the characteristics of the destinations. Additionally, the source of information about the destination used by each tourist before traveling is also considered as an essential element for the choice of transport.

\section{Models}

\subsection{Data Analysis Tools}

The architecture of this model and the sources of information are presented in this section. Based on the previous argument, Figure 1 illustrates the conceptual model hypothesized in this research, aiming at analyzing the relations between characteristics of tourists and trips, sources of information, and transportation choices in an urban destination. Since our analysis also aims at emphasizing the importance of information, only 
international tourists (normally with less knowledge about the destination and eventual language barriers) are taken into account.

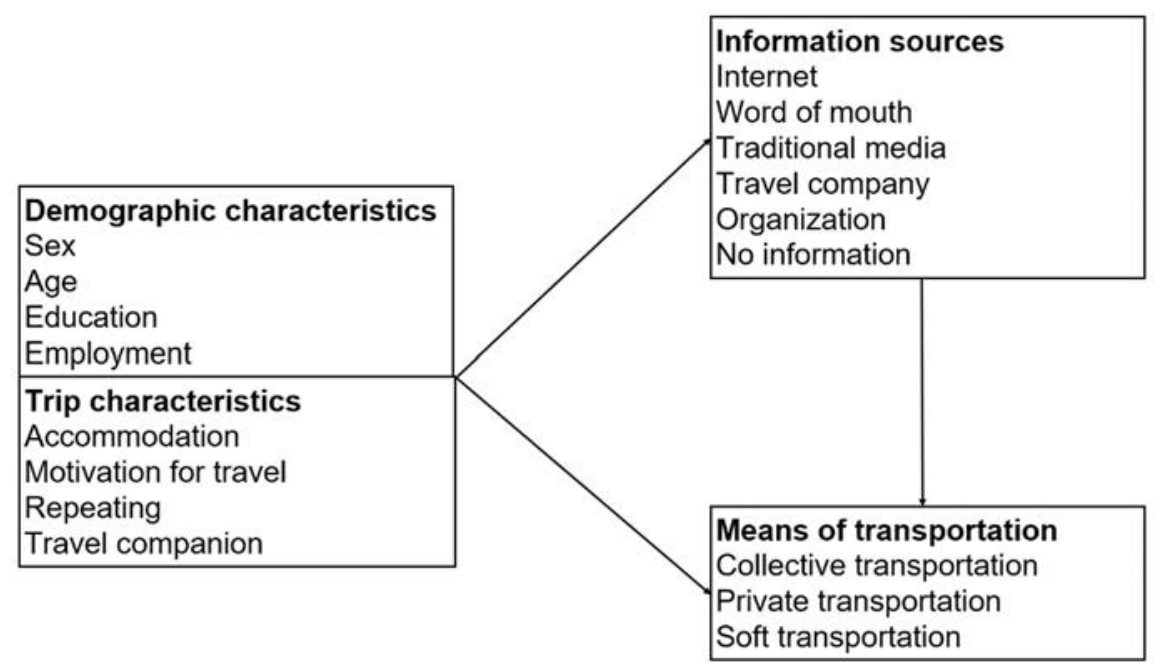

Figure 1. The proposed conceptual model.

Tourists visiting Barcelona were characterized by taking into consideration demographic elements and trip characteristics. For the demography, sex, age, level of education, and employment were considered, taking into account other studies on transportation choice in tourism destinations [15]. Similarly, the trips were characterized by taking into consideration common aspects included in tourism segmentation analysis, such as the selected accommodation, the motivation for travel, being a repeating visitor, and the travel companion.

In order to assess the aspects related to the previous knowledge about mobility in the destination, our analysis considered five main sources for international tourists to obtain local travel information in Barcelona: internet (web/social networks/blogs), word of mouth (family/friends/acquaintances), traditional media (paper travel guides/books/printed media), offline travel companies (travel agencies/tour operators/travel agency brochures/tour operators), and organizations (company/study center/association/choir/sports group/gifts and gift boxes or packs). However, tourists may also go to Barcelona without any information.

Regarding means of transportation, for the purposes of this research, the options were grouped into collective transportation, private transportation, and soft modes of transportation. Collective transportation includes metro, trains, trams, funiculars, car cables, regular buses, touristic buses, or long-distance buses. Taxis, private/rental cars, or car-sharing/pooling are types of private transportation. Soft traffic generally refers to non-motorized forms of mobility (or at least with very low levels of $\mathrm{CO}_{2}$ emissions), such as private, rental, or shared bicycles; private or rental motorcycles (which represent only $0.22 \%$ of our sample); or electric scooters.

In this study, both the dependent and independent variables were based on categorical data. As such, in order to investigate the paths between characteristics of tourists and trips, information sources, and means of transportation, a multinomial logistic regression was adopted [36,37]. The model was computed by using the Stata statistical program.

\subsection{Sampling}

Barcelona maintains high attractiveness for foreign tourists, and its infrastructures can bring a satisfying experience to foreign tourists [38]. Previous research recognized the important value of foreign tourists in the Barcelona tourism market [9]. Additionally, these travelers are normally less informed about the destination characteristics (including 
mobility options) than domestic visitors. Hence, this study selected foreign tourists in Barcelona as the research object.

The database used in this work included information obtained in 12.455 personal (face-to-face) interviews conducted by the City of Barcelona from February to December 2018 [39]. The composition of the sample took into consideration aspects such as the proportion of each month within the yearly tourism fluxes, tourists staying only in the city or visiting other places in the surroundings, or relative importance of places of interest when defining the locations to conduct the interviews. All tourists participating in this study reported that they had visited Barcelona, and their various travel experiences in the city were recorded. After discarding the data, including incomplete responses (i.e., missing data), a total of 6000 questionnaires were used for the final data analysis.

Table 1 details the profile of tourists in this research. There were more male travelers $(59.6 \%)$ than female travelers $(40.5 \%)$, and the majority had university degrees $(71.1 \%)$. The age of travelers was somewhat well distributed: less than $24,18.9 \%$; 25-34 years old, $33.9 \%$; 35-44 years old, $19.8 \%$; $45-54$ years old, $14.8 \%$; 55-64 years old, $8.7 \%$; more than 65 years old, $3.9 \%$. Regarding employment, the largest proportion $(61.0 \%)$ are employees, follow by employers $(20.1 \%)$, students $(11.0 \%)$, unemployed $(4.0 \%)$, and retried people (3.9\%). More than two-thirds of the travelers (67.7\%) selected conventional accommodation (including hotels, hostels, or camping sites) and traveled for leisure (69.4\%). A slight majority (52.1\%) had not previously visited Barcelona. Couples were the most frequent group arrangement (38.5\% of the tourists), but the proportion of people traveling alone was also close to one-third (28.3\%).

Table 1. Profile of tourists $(n=6000)$.

\begin{tabular}{|c|c|c|c|}
\hline Variable & Category & Frequency $(n)$ & Percent \\
\hline \multirow{2}{*}{ Sex } & Male & 3573 & 59.6 \\
\hline & Female & 2427 & 40.5 \\
\hline \multirow{6}{*}{ Age } & $\leq 24$ & 1134 & 18.9 \\
\hline & $2 \overline{5}-34$ & 2033 & 33.9 \\
\hline & $35-44$ & 1188 & 19.8 \\
\hline & $45-54$ & 889 & 14.8 \\
\hline & $55-64$ & 522 & 8.7 \\
\hline & $\geq 65$ & 234 & 3.9 \\
\hline \multirow{2}{*}{ Education } & University degree & 4264 & 71.1 \\
\hline & Other & 1736 & 28.9 \\
\hline \multirow{5}{*}{ Employment } & Employers & 1205 & 20.1 \\
\hline & Employees & 3661 & 61.0 \\
\hline & Retired & 235 & 3.9 \\
\hline & Students & 658 & 11.0 \\
\hline & Unemployed & 241 & 4.0 \\
\hline \multirow{3}{*}{ Accommodation } & $\begin{array}{c}\text { Conventional } \\
\text { accommodation }\end{array}$ & 4061 & 67.7 \\
\hline & Touristic apartments & 1098 & 18.3 \\
\hline & House of acquaintances & 841 & 14.0 \\
\hline \multirow{3}{*}{ Motivation for travel } & Professional & 1238 & 20.6 \\
\hline & Leisure & 4162 & 69.4 \\
\hline & Personal & 600 & 10.0 \\
\hline \multirow{2}{*}{ Repeating } & New visitors & 3126 & 52.1 \\
\hline & Repeat visitors & 2874 & 47.9 \\
\hline \multirow{4}{*}{ Travel companion } & Acquaintances & 1540 & 25.7 \\
\hline & Couples & 2308 & 38.5 \\
\hline & Workmates & 452 & 7.5 \\
\hline & Individual travelers & 1700 & 28.3 \\
\hline
\end{tabular}

\section{Results}

"In order to identify potential problems with the data (e.g., data scarcity), the previous researcher suggests checking the standard errors to confirm whether they are greater than 2.0 [36]". In the case of our model, all standard errors obtained by multinomial logistic 
regression in Sections 3.1 and 3.2 are below that threshold. In addition, scholars advise 10 samples for each independent variable, and it would be more appropriate for the number of samples to be 20 times the number of variables [40]. In this study, there are a total of 6000 samples, which surpasses the requirements of the research model.

\subsection{Multinomial Logistic Regression: Impacts of Demographic and Trip Characteristics on Information Sources and Transportation Choices}

First, we hypothesized that tourist and trip characteristics predict information sources and means of transportation. As the study utilizes a multinomial logistic regression analysis in which all variables are classified, specific reference categories are required in the dependent variables [36]. This study compares tourists who learned about Barcelona by using a specific information source with those who did not obtain any information before heading over to the city. In order to better observe collective and soft forms of transportation, private transportation is used as a reference category. Table 2 presents the regression coefficients and related significance levels.

Table 2. Characteristics associated with information and transportation in the multinomial logistic regression model.

\begin{tabular}{|c|c|c|c|c|c|c|c|c|c|}
\hline Response Variable & Internet & WOM & TM & Travel & Organization & ME (NI) & Collective & Soft & ME (Private) \\
\hline Male & -0.061 & -0.056 & -0.004 & -0.105 & 0.113 & 0.003 & $-0.230 * *$ & $-0.266^{*}$ & $0.039 * *$ \\
\hline Female & $0^{\mathrm{b}}$ & $0^{\mathrm{b}}$ & $0^{\mathrm{b}}$ & $0^{\mathrm{b}}$ & $0^{\mathrm{b}}$ & & $0^{\mathrm{b}}$ & $0^{\mathrm{b}}$ & \\
\hline$\leq 24$ & $0.799 *$ & 0.645 & 0.686 & -0.757 & 1.484 & -0.054 & $0.773 * *$ & $1.005 *$ & $-0.140 * *$ \\
\hline $25-34$ & $1.128 * *$ & $0.801 *$ & 1.301 & -0.518 & 1.154 & $-0.067^{*}$ & $0.652 * *$ & 0.704 & $-0.119^{* *}$ \\
\hline $35-44$ & $0.992 * *$ & 0.635 & 1.345 * & 0.026 & 1.282 & $-0.063 *$ & 0.290 & 0.468 & -0.059 \\
\hline $45-54$ & 0.548 & 0.265 & 1.193 & -0.238 & 0.914 & -0.038 & 0.209 & 0.414 & -0.045 \\
\hline $55-64$ & 0.249 & -0.004 & 0.228 & -0.064 & 1.191 & -0.021 & 0.053 & 0.277 & -0.146 \\
\hline$\geq 65$ & $0^{\mathrm{b}}$ & $0^{\mathrm{b}}$ & $0^{\mathrm{b}}$ & $0^{\mathrm{b}}$ & $0^{\mathrm{b}}$ & & $0^{\mathrm{b}}$ & $0^{\mathrm{b}}$ & \\
\hline University degree & $0.542 * *$ & $0.425 * *$ & $0.602 *$ & 0.092 & 0.263 & $-0.030 * *$ & 0.063 & -0.113 & -0.008 \\
\hline Other & $0^{\mathrm{b}}$ & $0^{\mathrm{b}}$ & $0^{\mathrm{b}}$ & $0^{\mathrm{b}}$ & $0^{\mathrm{b}}$ & & $0^{\mathrm{b}}$ & $0^{\mathrm{b}}$ & \\
\hline Employer & $0.749^{* *}$ & $0.686^{*}$ & 1.391 & $1.501 * *$ & 0.982 & $-0.060^{* *}$ & -0.242 & -0.111 & 0.038 \\
\hline Employee & 0.534 * & 0.424 & 1.304 & $1.283^{* *}$ & $1.580^{*}$ & $-0.050 *$ & -0.175 & -0.345 & 0.032 \\
\hline Retired & 0.512 & 0.632 & $2.749 * *$ & $1.522 * *$ & $-a^{-a}$ & -0.049 & $-0.552 *$ & -0.626 & $0.100^{*}$ \\
\hline Students & $0.694^{*}$ & $0.679 *$ & $2.225 * *$ & $1.144 *$ & $2.373^{* *}$ & $-0.064^{* *}$ & 0.319 & -0.109 & -0.042 \\
\hline Unemployed & $0^{\mathrm{b}}$ & $0^{\mathrm{b}}$ & $0^{\mathrm{b}}$ & $0^{\mathrm{b}}$ & $0^{\mathrm{b}}$ & & $0^{\mathrm{b}}$ & $0^{\mathrm{b}}$ & \\
\hline $\begin{array}{l}\text { Conventional } \\
\text { accommodation }\end{array}$ & $0.646 * *$ & $-0.475^{* *}$ & 0.917 * & $0.993 * *$ & $2.048 * *$ & $-0.039 * *$ & $-0.756^{* *}$ & $-0.872 * *$ & $0.120^{* *}$ \\
\hline Touristic apartments & $0.915 * *$ & -0.004 & 0.801 & -0.126 & $1.350 * *$ & $-0.047^{* *}$ & -0.200 & $-0.491^{*}$ & 0.031 \\
\hline House of acquaintances & $0^{\mathrm{b}}$ & $0^{\mathrm{b}}$ & $0^{\mathrm{b}}$ & $0^{\mathrm{b}}$ & $0^{\mathrm{b}}$ & & $0^{\mathrm{b}}$ & $0^{\mathrm{b}}$ & \\
\hline Professional & -0.300 & $-0.871^{* *}$ & 0.450 & 0.210 & $1.174^{* *}$ & 0.015 & $-1.036^{* *}$ & $-1.002 * *$ & $0.204^{* *}$ \\
\hline Leisure & $0.480^{* *}$ & 0.273 & $1.471 * *$ & 0.513 & $-1.732 * *$ & $-0.025 *$ & 0.014 & 0.174 & -0.004 \\
\hline Personal & $0^{\mathrm{b}}$ & $0^{\mathrm{b}}$ & $0^{\mathrm{b}}$ & $0^{\mathrm{b}}$ & $0^{\mathrm{b}}$ & & $0^{\mathrm{b}}$ & $0^{\mathrm{b}}$ & \\
\hline New visitors & $0.820 * *$ & $0.993 * *$ & $1.134 * *$ & $1.032 * *$ & $0.902 * *$ & $-0.050 * *$ & 0.200 ** & $-0.241 *$ & $-0.027^{*}$ \\
\hline Repeat visitors & $0^{\mathrm{b}}$ & $0^{\mathrm{b}}$ & $0^{\mathrm{b}}$ & $0^{\mathrm{b}}$ & $0^{\mathrm{b}}$ & & $0^{\mathrm{b}}$ & $0^{\mathrm{b}}$ & \\
\hline Acquaintances & -0.012 & 0.156 & 0.263 & 0.424 & 0.204 & -0.005 & $-0.325^{* *}$ & $-0.726^{* *}$ & $0.060 * *$ \\
\hline Couple & $0.498^{* *}$ & 0.287 & 0.517 & $0.592 * *$ & -0.431 & $-0.024 * *$ & $-0.191 *$ & -0.305 & $0.033 *$ \\
\hline Workmates & -0.393 & -0.559 & -0.571 & $0.640 *$ & 0.342 & 0.020 & $-0.364 * *$ & 0.111 & $0.051 *$ \\
\hline Individual travelers & $0^{\mathrm{b}}$ & $0^{\mathrm{b}}$ & $0^{\mathrm{b}}$ & $0^{\mathrm{b}}$ & $0^{\mathrm{b}}$ & & $0^{\mathrm{b}}$ & $0^{\mathrm{b}}$ & \\
\hline
\end{tabular}

Notes: The reference categories: NI-no information and private transportation; Abbreviations: WOM-word of mouth, TM-traditional media, ME-marginal effects; Significance levels: ${ }^{* *} p<0.01 ;{ }^{*} p<0.05$. ${ }^{\text {a }}$ The response variable does not contain this category. ${ }^{\mathrm{b}}$ This parameter is set to zero because it is redundant.

Our analysis finds that conventional travel companies are still a relevant source of information for all groups of tourists. However, the internet has also a generalized use, except for the oldest travelers (retired). Travels promoted by organizations are relevant for students (student tours) and employees (professional trips), while word of mouth constitutes a relevant source of information for employers and students, leading, in both cases, to a preference for non-conventional forms of accommodation.

The generational divide slightly observed for the sources of information (retired tourists less oriented to digital sources) is more pronounced when looking at transport choices, with young people (less than 35 years old) more oriented to collective transports and, to a larger extent (less than 24 years old), to soft modes of transportation. These results suggest that although age may influence a certain impact on choices and behavior patterns, this effect may be diluted in the long run, as also observed for the utilization of the internet 
(not anymore an exclusive of the youngest tourists but now generally used by almost all the groups). A similar effect may happen with the preference for more sustainable forms of transport (collective and soft modes), which requires further analysis in the future.

It is noteworthy that the choice of collective transports is related to all sources of characteristics and unrelated to the level of education. However, traveling in groups (any kind of group) reduces the preference for collective transports. As expected, retired tourists also have a lower preference for this option. Interestingly, it is observed that first-time visitors prefer collective transports but not soft modes of mobility. This suggests that the public transports in the city are easy to use and supported by appropriate information, which allows for their utilization without previous experience. In addition, the marginal effect highlights that tourists who are professionally motivated, use traditional accommodation, or are retired prefer private transportation, which also shows that people with sufficient financial support would take private transportation for the sake of personal space or less traffic transfer.

In general, our results reveal a relatively slow tendency for a more sustainable choice of modes of transportation in urban destinations, with the youngest travelers adopting new behavioral patterns oriented to collective and soft modes of mobility.

\subsection{Multinomial Logistic Regression: Impacts of Information on Transportation Choices}

Second, we confirm the associations between information sources and means of transportation, as represented in the conceptual model in Figure 1. This part contributes to meaningful insights into current transport modes and the future promotion of clean energy transport. In line with the previous part, private transportation was also set as the reference. The results in Table 3 reveal that tourists who received information about tourism in Barcelona from traditional media are most likely to choose collective transportation, followed by the internet and word of mouth. Those following organizations or travel companies prefer private transportation over collective transportation or soft modes of transportation. Additionally, the marginal effect also clearly supplements the relationship between the information sources and the choices of destination transportation. In particular, travel companies have the greatest positive influence, which indicates that when destinations promote more environmentally friendly public transportation or soft transportation, destinations also need to pay attention to tourists who travel to Barcelona through this channel.

Table 3. Information associated with transportation in the multinomial logistic regression model.

\begin{tabular}{cccc}
\hline Response Variable & Collective Transportation & Soft Transportation & Marginal Effects (Private) \\
\hline Internet & $0.638^{* *}$ & 0.050 & $-0.113^{* *}$ \\
Word of mouth & $0.609^{* *}$ & -0.186 & $-0.105^{* *}$ \\
Traditional media & $1.150^{* *}$ & -1.754 & $-0.178^{* *}$ \\
Travel company & $-0.327^{*}$ & $-0.571^{*}$ & $0.836^{*}$ \\
Organization & $-0.653^{* *}$ & $-0.811^{* *}$ & $0.162^{* *}$ \\
No information & $0^{\text {a }}$ & $0^{\text {a }}$ & \\
\hline
\end{tabular}

Notes: The reference category: private transportation; Significance levels: ${ }^{* *} p<0.01 ;{ }^{*} p<0.05 .{ }^{\text {a }}$ This parameter is set to zero because it is redundant.

The research findings indicate that tourists who spend time on their own inquiry to obtain tourism information are more willing to use collective transportation. Compared with private transportation, collective transportation may take more time but are costeffective. The impact on soft transportation induced by the internet among the information sources is the only positive path, although it is not significant. This highlights that the internet is potentially the most useful communication channel to promote soft modes of transport in Barcelona. 


\section{Discussion}

The main objectives of this work were to analyze and to discuss three inter-related questions: how demographic features of tourists and trip characteristics influence the sources of information used before the trip; what implications these demographic and trip characteristics may have on transport choice at the destination (both in Section 4.1); and how information sources influence transport preferences in urban tourism (Section 4.2). Within this framework, we gave particular attention to the role of non-motorized forms of transport.

Regarding the first question, we observed that the generational divide regarding the utilization of digital tools tends to reduce with time. In fact, our analysis found that only the oldest age groups (retired tourists) were not oriented to the use of information and communication technologies. Thus, a full generalization of the utilization of digital tools can eventually occur in a relatively short time.

For the second broad question under analysis (how tourist and trip characteristics impact transport choices), we observed a larger generational divide, with younger groups clearly preferring collective transports (tourists under 34 years old) and soft modes of transportation (tourists under 24 years old) in relation to private cars. This generational divide may eventually dilute in the future, as it happened with digital tools. However, in the current situation, it is clear that a more sustainable approach to transport and mobility in urban tourism destinations is mostly pursued by the youngest travelers.

Regarding the trip characteristics, it is relevant to mention-due to its potential direct impacts on destination marketing and communication strategies-that group travelers tend to be less oriented both to collective or soft modes of transport than individual travelers. Moreover, our study also found that previous knowledge about the city is not a relevant obstacle for the utilization of collective transports by first-time visitors, but it has a negative impact on the preference for soft modes of transport.

Finally, our third bread research question was about the impact of sources of information on the choice of transport modes, being noteworthy that diverse communication channels (traditional media, internet, and word of mouth) may lead to the preference for collective transports. Similarly, devoting some time to individual research about the destination before traveling also has a clear positive impact on the utilization of collective transports, whereas relying on travel companies or other organizations tends to lead to the utilization of private cars, which also opens a significant potential for specific marketing and communication strategies. As a new form of tourism mobility and clearly preferred by the youngest groups, the utilization of soft modes of transportation only has a relevant correlation with the internet as a source of information for travel.

\section{Conclusions}

Although several previous studies looked into the preference for soft modes of transportation in urban tourism destinations, the focus was mostly on the characteristics of the cities and related infrastructures and services, both for bicycles [24,28] and for pedestrians [32-35], rather than the characteristics, motivations, or sources of information of the travelers. Our analysis offers an innovative contribution to the literature by revealing the significant impacts of these aspects in the city of Barcelona. These findings are particularly relevant when it is observed that the sustainability of urban tourism requires an important effort for the mitigation of $\mathrm{CO}_{2}$ emissions and other environmental and social problems (such as traffic congestion or overutilization of spaces, services, and infrastructures) raised by tourism in contemporary cities.

In general terms, the previously mentioned studies revealed that soft (or non-motorized) forms of transportation can be more time-consuming, but they potentially contribute to a higher enjoyment of the local landscapes $[25,27]$. Thus, apart from protecting the environment and reducing negative impacts on local communities, these forms of mobility may also contribute to the achievement of a more satisfactory tourist experience. By identifying specific behaviors and preferences for different segments and communications channels 
within the tourism market, our study offers relevant policy and managerial implications for the reorganization of tourism activities more efficiently and sustainably when traveling restrictions are reduced after the effects of the COVID-19 pandemics on international mobility.

Our results reveal that the youngest travelers are those more oriented for the utilization of collective or soft forms of mobility, which makes them a priority group in terms of promoting these environmentally friendly transport modes for urban tourism. Although some years ago, it was observed that these groups were the most active using internet to collect travel information, today we can observe that almost all the group ages are familiar with digital tools to access information. Thus, it is a matter of further research whether this preference revealed by the youngest groups expands to all ages in the future or if it remains concentrated in this specific group.

On the contrary, it was observed that the group travels, organized by conventional tourism agencies or other companies, are linked to the preference for private forms of transportation. This aspect clearly reveals the importance of the development of new services or the reinforcement and improvement of communication strategies oriented to these types of companies, so as to show that group visits can also be supported by soft forms of mobility and collective transports. On the other hand, tourists researching information by themselves by using digital sources are already more oriented towards the utilization of collective forms of transport.

It is also noteworthy that first-time visitors do not experience significant problems using collective transports, but they tend not to prefer soft modes of transportation. Considering that this type of mobility is mostly adopted by the youngest market segments, specific marketing and communication strategies based on digital tools can be developed to address this problem.

Previous research undertaken in the city of Barcelona [9] revealed that the satisfaction achieved with the trip can be enhanced through the utilization of public transports. Although there are some suggestions in the literature that a similar phenomenon may happen with the preference for soft modes of transportations, the number of tourists using these forms of transport is still relatively low, imposing great difficulties in undertaking a detailed analysis. Thus, this is another important aspect for further research.

Author Contributions: Data curation, methodology, software, and formal analysis: Y.B.; Conceptualization, validation, and supervision: J.R.; Investigation, original draft preparation, review, and editing: Y.B. and J.R. All authors have read and agreed to the published version of the manuscript.

Funding: This research received no external funding.

Institutional Review Board Statement: Not applicable.

Informed Consent Statement: Not applicable.

Data Availability Statement: Data are available on request.

Conflicts of Interest: The authors declare no conflict of interest.

\section{References}

1. Gössling, S.; Scott, D.; Hall, C.M. Challenges of tourism in a low-carbon economy. Wiley Interdiscip. Rev. Clim. Chang. 2013, 4, 525-538. [CrossRef]

2. Hall, C.M.; Le-Klähn, D.-T.; Ram, Y. Tourism, Public Transport and Sustainable Mobility; Channel View Publications: Bristol, UK, 2017.

3. World Tourism Organization. Climate Change and Tourism-Responding to Global Challenges; UNWTO: Madrid, Spain, 2008.

4. World Tourism Organization and International Transport Forum. Transport-Related $\mathrm{CO}_{2}$ Emissions of the Tourism Sector-Modelling Results; UNWTO: Madrid, Spain, 2019.

5. OECD. Financing Climate Objectives in Cities and Regions to Deliver Sustainable and Inclusive Growth; OECD: Paris, France, 2019.

6. Prideaux, B. The role of the transport system in destination development. Tour. Manag. 2000, 21, 53-63. [CrossRef]

7. Gronau, W.; Kagermeier, A. Key factors for successful leisure and tourism public transport provision. J. Transp. Geogr. 2007, 15, 127-135. [CrossRef]

8. Albalate, D.; Bel, G. Tourism and urban public transport: Holding demand pressure under supply constraints. Tour. Manag. 2010, 31, 425-433. [CrossRef] 
9. Romão, J.; Bi, Y. Determinants of collective transport mode choice and its impacts on trip satisfaction in urban tourism. J. Transp. Geogr. 2021, 94, 103094. [CrossRef]

10. Thompson, K.; Schofield, P. An investigation of the relationship between public transport performance and destination satisfaction. J. Transp. Geogr. 2007, 15, 136-144. [CrossRef]

11. Loo, B.P.Y. Walking towards a happy city. J. Transp. Geogr. 2021, 93, 103078. [CrossRef]

12. Prillwitz, J.; Barr, S. Moving towards sustainability? Mobility styles, attitudes and individual travel behaviour. J. Transp. Geogr. 2011, 19, 1590-1600. [CrossRef]

13. Masiero, L.; Zoltan, J. Tourists intra-destination visits and transport mode: A bivariate probit model. Ann. Tour. Res. 2013, 43, 529-546. [CrossRef]

14. Le-Klähn, D.-T.; Gerike, R.; Hall, C.M. Visitor users vs. non-users of public transport: The case of Munich, Germany. J. Destin. Mark. Manag. 2014, 3, 152-161. [CrossRef]

15. Le-Klähn, D.-T.; Hall, C.M. Tourist use of public transport at destinations-A review. Curr. Issues Tour. 2015, 18, 785-803. [CrossRef]

16. European Commission. The European Green Deal: Sustainable Mobility. Available online: https://ec.europa.eu/commission/ presscorner/detail/en/fs_19_6726 (accessed on 12 March 2021).

17. Autoritat del Transport Metropolità. Informe Consell d'Administració ("Report of the Administration Council"); Autoritat del Transport Metropolità: Barcelona, Spain, 2017.

18. City of Barcelona. Externalitats Ambientals del Turisme de la Ciutat de Barcelona ("Environmental Externalities from Tourism in the City of Barcelona"); City of Barcelona: Barcelona, Spain, 2019.

19. City of Barcelona. Estratègia de Mobilitat Turística ("Strategy for Tourism Mobility"); City of Barcelona: Barcelona, Spain, 2018.

20. Metropolitan Area of Barcelona. Metropolitan Plan for Urban Mobility 2019-2024; Metropolitan Area of Barcelona: Barcelona, Spain, 2019.

21. Pearce, D.G. Tourist time-budget. Ann. Tour. Res. 1988, 15, 106-121. [CrossRef]

22. Lew, A.; McKercher, B. Modeling tourist movements: A local destination analysis. Ann. Tour. Res. 2006, 33, 403-423. [CrossRef]

23. Le-Klähn, D.-T. Public Transport. In The Routledge Handbook of Tourism Sustainability; Hall, C.M., Gossling, S., Scott, D., Eds.; Routledge: London, UK, 2015.

24. Pucher, J.; Buehler, R. Making cycling irresistible: Lessons from the Netherlands, Denmark and Germany. Transp. Rev. 2008, 28, 495-528. [CrossRef]

25. Lee, C.-F.; Chen, P.-T.; Huang, H.-I. Attributes of destination attractiveness in Taiwanese bicycle tourism: The perspective of active experienced bicycle tourists. Int. J. Hosp. Tour. Adm. 2014, 15, 275-297. [CrossRef]

26. Han, H.; Meng, B.; Kim, W. Bike-traveling as a growing phenomenon: Role of attributes, value, satisfaction, desire, and gender in developing loyalty. Tour. Manag. 2017, 59, 91-103. [CrossRef]

27. Lee, C.-F.; Huang, H.-I. The attractiveness of Taiwan as a bicycle tourism destination: A supply-side approach. Asia Pac. J. Tour. Res. 2014, 19, 273-299. [CrossRef]

28. Nilsson, J.H. Urban bicycle tourism: Path dependencies and innovation in Greater Copenhagen. J. Sustain. Tour. 2019, 27, 1648-1662. [CrossRef]

29. Hall, C.M.; Ram, Y. Walk score ${ }^{\circledR}$ and its potential contribution to the study of active transport and walkability: A critical and systematic review. Transp. Res. Part D Transp. Environ. 2018, 61, 310-324. [CrossRef]

30. Arslan, T.V.; Durak, S.; Gebesce, F.D.; Balcik, B. Assessment of factors influencing walkability in shopping streets of tourism cities: Case of Bursa, Turkey. Int. J. Tour. Cities 2018, 4, 330-341. [CrossRef]

31. Gorrini, A.; Bertini, V. Walkability assessment and tourism cities: The case of Venice. Int. J. Tour. Cities 2018, 4, 355-368. [CrossRef]

32. Henderson, J. Making cities more walkable for tourists: A view from Singapore's streets. Int. J. Tour. Cities 2018, 4, 285-297. [CrossRef]

33. Ujang, N.; Muslim, Z. Walkability and attachment to tourism places in the city of Kuala Lumpur, Malaysia. Athens J. Tour. 2014, 2, 53-65. [CrossRef]

34. Lwin, K.K.; Murayama, Y. Modelling of urban green space walkability: Eco-friendly walk score calculator. Comput. Environ. Urban Syst. 2011, 35, 408-420. [CrossRef]

35. Hall, C.M.; Ram, Y. Measuring the relationship between tourism and walkability? Walk Score and English tourist attractions. J. Sustain. Tour. 2019, 27, 223-240. [CrossRef]

36. Field, A. Discovering Statistics Using IBM SPSS Statistics; Sage: London, UK, 2013.

37. Starkweather, J.; Moske, A.K. Multinomial Logistic Regression. 2011, 29, pp. 2825-2830. Available online: http:/ / www.unt.edu/ rss/class/Jon/Benchmarks/MLR_JDS_Aug2011.pdf (accessed on 10 September 2021).

38. Garín-Muñoz, T.; Moral, M.J. Determinants of satisfaction with an urban tourism destination: The case of Barcelona. J. Rev. Glob. Econ. 2017, 6, 113-128. [CrossRef]

39. Barcelona City Council. Tourists Barcelona; City Council: Barcelona, Spain, 2018.

40. Hosmer, J.; David, W.; Lemeshow, S.; Sturdivant, R.X. Applied Logistic Regression; John Wiley \& Sons: Hoboken, NJ, USA, 2013; Volume 398. 